\title{
Anterior Fusion using a Vascularized Fibular Graft for Cervical Kyphosis Associated with Neurofibromatosis Type 1: A Report of Two Cases with Long-term Follow-up
}

Gentaro Kumagai ${ }^{1}$, Naoki Echigoya ${ }^{1}$, Kanichiro Wada ${ }^{1}$, Toru Asari ${ }^{1}$, Satoshi Toh ${ }^{1}$, Yasuyuki Ishibashi ${ }^{1}$

Learning Point of the Article:

Anterior fusion with VFG for cervical kyphosis associated with NF-1 can achieve good bone union and maintain long-term alignment. However, it is important to watch for vascular events related to NF-1.

\section{Abstract}

Introduction: Vascularized fibular grafts (VFG) in the cervicothoracic spine have been used for patients with progressive neurofibromatosis (NF) type-1-related kyphosis, but the long-term outcomes of VFG with NF-1 are not well described. We describe the long-term follow-up of two cases of cervical kyphosis related to NF-1 treated with VFG in the cervical spine.

Case Report: Case 1 was that of a 33-year-old man with a large neurofibroma at the back of his neck and an arteriovenous malformation at C2-7. The neurofibroma was resected by durotomy and intradural neurofibromas were extirpated through O-C6 laminectomy. Anterior fusion with VFG was performed 6 months later, and bone union was confirmed after 4 months. Cervical alignment was maintained with $50^{\circ}$ kyphosis 15 years after the operation. The man suffered a subarachnoid hemorrhage 22 years after the operation. Case 2 was a 23 -year-old woman with diastematomyelia at C6-T1 who was treated by anterior fusion with VFG at C4-T1. The diastematomyelia septum was resected through a $\mathrm{C} 4-\mathrm{T} 1$ laminectomy with simultaneous posterolateral fusion at C3-T2. Cervical alignment was maintained with $50^{\circ} \mathrm{kyphosis} 18$ years later. The left vertebral artery ruptured and was embolized 10 years after the operation.

Conclusion: Anterior fusion with VFG can achieve good bone union and maintains long-term alignment. However, it is important to watch for vascular events related to NF-1.

Keywords: Vascularized fibular graft, cervical kyphosis, neurofibromatosis type 1.

\section{Introduction}

Spinal deformities are frequent in neurofibromatosis type 1 (NF-1), also called von Recklinghausen's disease. Dystrophic changes in the spine make it difficult to achieve good spinal alignment and bone union in spinal surgery for patients with NF-1, and the results are poor for cases with severe deformity. In many instances, the vertebral column can be stabilized through posterior fixation. In other cases, posterior fixation is either mechanically unfeasible or subsequently proves to be inadequate due to breakage [1]. Vascularized fibular grafts (VFG) in the cervicothoracic spine have been used for patients with progressive NF-1-related kyphosis [1, 2], but the long- term outcomes of VFG with NF-1 are not well described. Here, we describe two long-term follow-up cases of cervical spine VFG for NF-1-related cervical kyphosis.

\section{Case Report}

\section{Case 1}

\section{Presentation}

A man began noticing neck pain when he was 23 years old, and cervical kyphosis was noted when he visited a clinic. He was diagnosed with NF-1 at age 30 . He developed paralysis in both arms and was treated by skull traction, but the paralysis

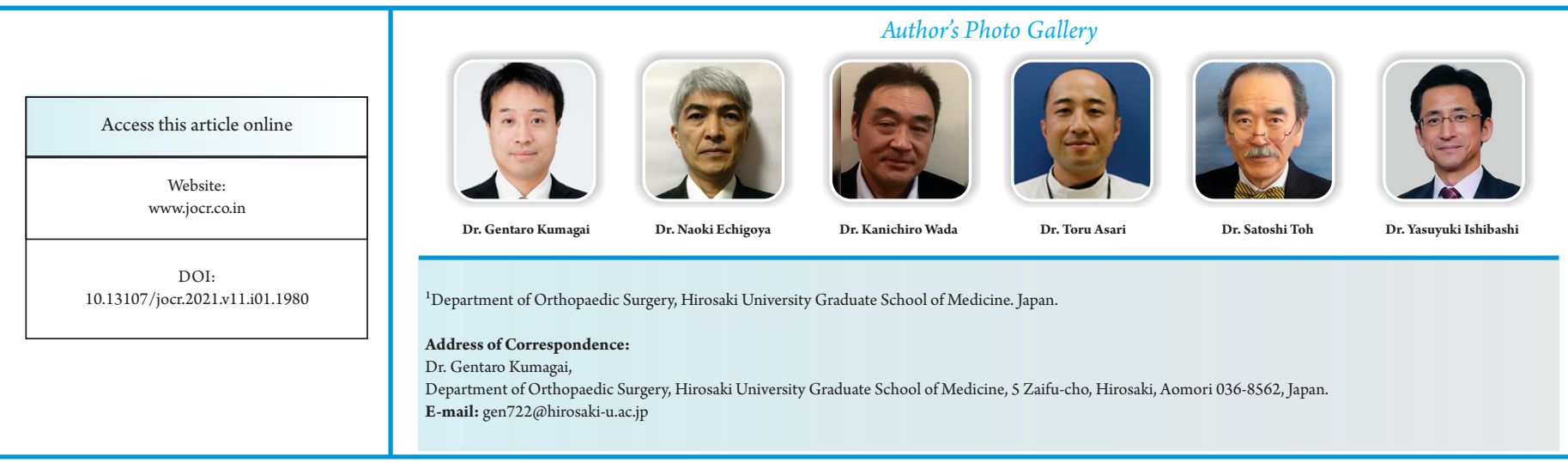

Journal of Orthopaedic Case Reports | pISSN 2250-0685 | eISSN 2321-3817 | Available on www.jocr.co.in | doi:10.13107/jocr.2021.v11.i01.1980 This is an Open Access article distributed under the terms of the Creative Commons Attribution Non-Commercial License (http://creativecommons.org/licenses/by-nc/3.0) which permits unrestricted non-commercial use, distribution, and reproduction in any medium, provided the original work is properly cited. 
progressed to quadriplegia. He was referred to our department when he was 33 years old. His paralysis progressed to pentaplegia at age 33 years. He was admitted to the hospital at age 33.

\section{Examination}

There was a huge neurofibroma at the back of his neck (Fig. 1a). The strength of his bilateral trapezius was Grade 3 at the C3 level and below. A lateral X-ray showed $45^{\circ}$ cervical kyphosis at C3-6 with dystrophic changes (Fig. 1b) and angiograms showed an arteriovenous malformation at C2-7 (Fig. 1c).

\section{Operation}

The arteriovenous malformation was embolized before surgery. The neck tumor and intradural neurofibromas were resected after O-C6 laminectomy. The patient was advised to wear a Trippi vest after the operation. Bilateral limb strength was Grade 5 after surgery. However, the kyphotic deformity progressed to $60^{\circ}$, and 6 months after the first operation (Fig. 1c), the patient underwent anterior fusion with VFG at $\mathrm{C} 2-\mathrm{C} 7$ (Fig. 1d).

\section{Post-operative course}

Bone union was confirmed by lateral X-ray 4 months later, and the Trippi vest was removed. He lived independently and worked as a mail carrier for 15 years after the second operation with no neurological disturbance. He had no neck pain or numbness in his arms, with a visual analog scale (VAS) of 50 $\mathrm{mm}$ on the right and $80 \mathrm{~mm}$ on the left. His bilateral limb strength was Grade 5. His Japanese Orthopedic Association (JOA) score was 15.5, with motor function scores of four for the upper (MU) and lower (ML) extremities and sensory

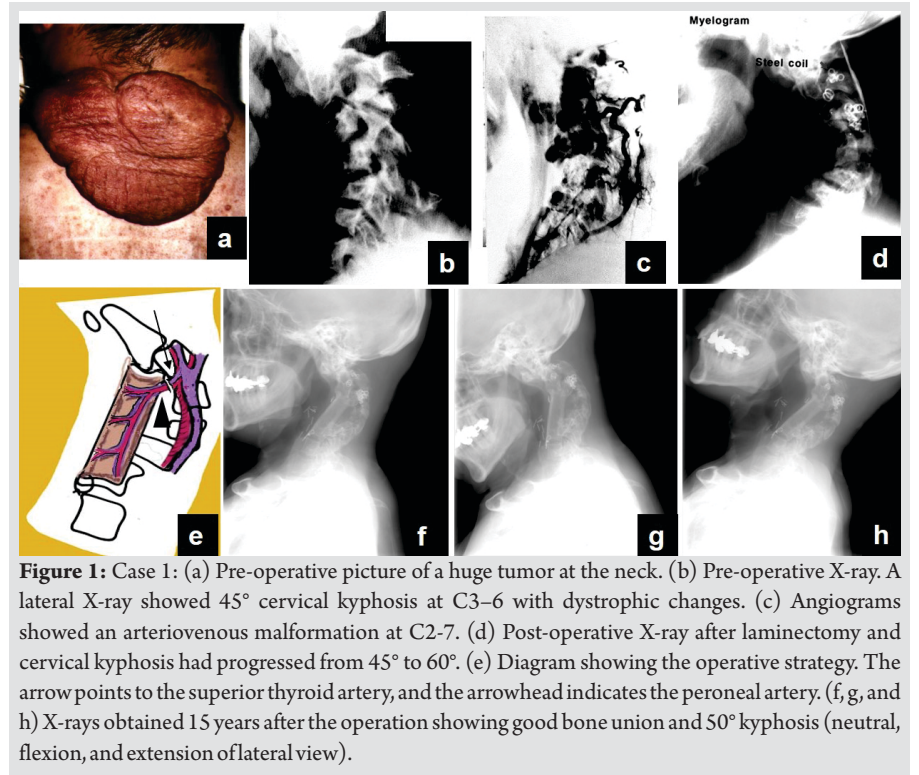

function scores of 1.5 in the upper extremities (SU), two in the trunk (ST), and two in the lower extremities (SL). His bladder function (BL) score was 2 . When he was examined 15 years after the operation, a lateral X-ray showed atlantoaxial subluxation and $50^{\circ}$ kyphosis (Fig. 1e-h). He suffered a subarachnoid hemorrhage 22 years after the operation. He quit his job and was unable to live independently.

\section{Case 2}

\section{Presentation}

A 22-year-old woman was referred to our department with progressive myelopathy. She had been diagnosed with NF-1 at age 13 , and a neck deformity was noted at a clinical visit when she was 19. She was admitted to the hospital at age 23 years.

\section{Examination}

Bilateral deep tendon reflexes were brisk with numbness on bilateral index fingers on neck flexion. Her bilateral limb strength was Grade 5. A lateral X-ray showed a $60^{\circ}$ cervical kyphosis with dystrophic changes at C4-7 (Fig. 2a). Magnetic resonance imaging (MRI) showed diastematomyelia at C6-T1 (Fig. 2b).

\section{Operation}

A Trippi vest was indicated before the surgery. She underwent simultaneous anterior and posterior operations: Resection of the septum of diastematomyelia by C4-T1 laminectomy and posterolateral fusion at $\mathrm{C} 3-\mathrm{T} 2$, followed by anterior fusion with VFG at C4-T1. The wave on the spinal cord evoked potential disappeared during the anterior procedure.

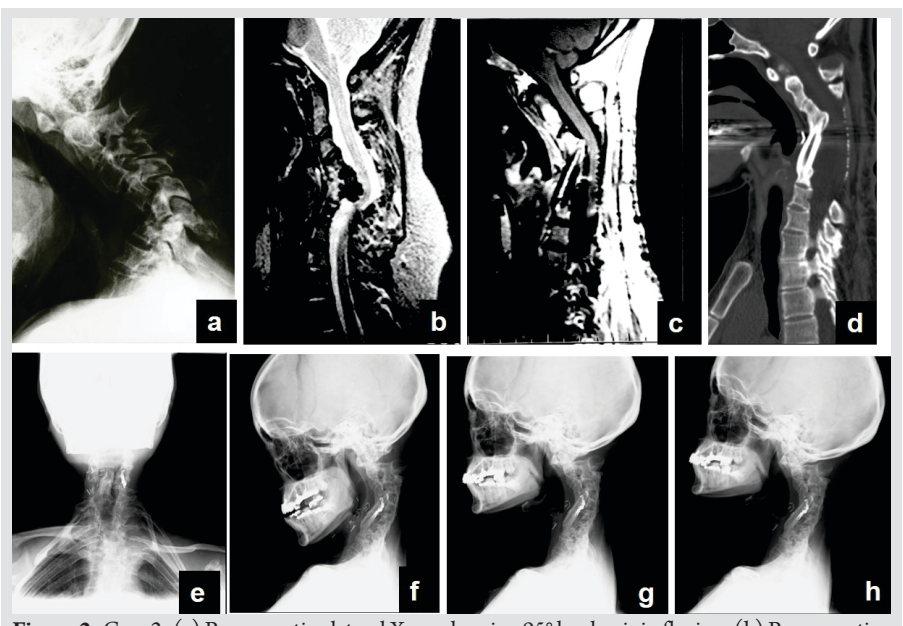

Figure 2: Case 2: (a) Pre-operative lateral X-ray showing $95^{\circ} \mathrm{kyphosis} \mathrm{in} \mathrm{flexion.} \mathrm{(b)} \mathrm{Pre-operative}$ midsagittal magnetic resonance imaging (MRI) showing diastematomyelia at C6-T1. (c) Postoperative midsagittal MRI showing decompression of spinal cord at C6-T1. (d-h) Computed tomography and X-ray images obtained 18 years after the operation showing good bone union and global alignment (coronal and neutral, flexion, and extension of lateral view) 


\section{Post-operative course}

The patient developed quadriplegia after the operation. Postoperative MRI showed sufficient decompression of the spinal cord (Fig. 2c). Therefore, she was observed without additional operation. Her paralysis gradually improved. Her bilateral limb strength was Grade 5 and she was ambulatory when discharged. The patient was advised to wear a Trippi vest for three months, an Adfit brace for five months, an orthocollar for one month, and a soft collar for 2 months. It took about a year to achieve solid fusion. The kyphosis was corrected to $30^{\circ}$ immediately after surgery but was at $50^{\circ}$ when bone union was achieved. Ten years after the operation, she suffered a rupture in her left vertebral artery and was treated by embolization with no neurological disturbance. She lived independently for 18 years after the operation with no neurological disturbance. She had no neck pain or numbness in her left upper extremity (VAS 80 $\mathrm{mm})$. Her bilateral limb strength was Grade 5 and her JOA score was 6.5 (MU 1, ML 2.5, SU 0, ST 0, SL 0, and BL 3). Computed tomography and X-ray showed that cervical alignment had been maintained with $50^{\circ}$ kyphosis (Fig. 2d-h).

\section{Discussion}

In these two cases of NF-1-related cervical kyphosis, anterior fusion with VFG effectively achieved good bone union and maintained long-term alignment. However, it is important to watch for vascular events related to NF-1.

The frequency of spinal deformity in NF-1 has been reported to be from $10 \%$ to $60 \%$ [3]. Severe scoliosis is associated with dystrophic changes [3], and most cases include kyphotic deformities. It is difficult to correct NF-1-related kyphosis and maintains alignment using posterior fusion only; additional anterior fusion is recommended [4]. Winter et al. evaluated the results of anterior and posterior fusion for cases of spinal kyphosis with a curvature of $80^{\circ}$ or more and reported that an average kyphosis of $126^{\circ}$ was corrected to $70^{\circ}$ after surgery and was finally maintained at $81^{\circ}[5]$. Anterior and posterior fusion is indicated for a curvature of $50^{\circ}$ or more, which is associated with significant dystrophic changes. Most reports of treatment for NF-1-related kyphosis involve thoracic rather than cervical kyphosis. We found 62 reported cases of NF-1-related cervical kyphosis, in which the average age was 21.8 years and the average angle was $71.4^{\circ}$ before surgery. These patients tended to be older than those with idiopathic scoliosis. Most reports were small case series and did not describe treatment or follow-up in detail. Craig and Govinder [6] reported that of eight cases of cervical kyphosis associated with NF-1, five had a curve greater than $90^{\circ}$, and that in one case, bone union was not achieved despite treatment by anterior and posterior fusion. Surgical outcomes are poor for severe deformity, and it is best to operate early before the deformity progresses [7].

Successful bone grafts require a good technical strategy. Bone from the rib, fibula, or iliac crest is used for thoracic or thoracolumbar fusion, and bone from the iliac crest or fibula is used for cervical fusion. Most cases require multilevel corpectomies, for which a fibular graft is a better choice. However, free fibular grafts take a long time to achieve bone union, and Bradford et al. reported that four of the 23 free fibular grafts showed fatigue fractures [8]. VFG has been used successfully for multilevel fusion [4], including anterior fusion with VFG for multilevel decompression and fusion in ossification of the posterior longitudinal ligament or severe kyphotic deformity after laminectomy [9]. VFG has also been used for fusion of the dystrophic NF-1 spine [1]. Vascularized rib grafts have been used for the anterior fusion of thoracic or thoracolumbar kyphosis [10]. However, rib bone is not structurally strong enough to support the cervical spine; the fibula provides a stronger graft and has a more suitable shape than the rib. Nijland et al. [11] reported that VFG provided good results for cervical kyphosis associated with NF-1. Iliac crest grafts have been reported [2]; however, 4 months after surgery, bone union was achieved in only $15 \%$ of iliac crest grafts compared to $70 \%$ of VFG cases. Bone union is poor in cases of fusion of three or more levels, and VFG is recommended rather than iliac crest for grafts of $5 \mathrm{~cm}$ or more [12]. VFG can be anastomosed to the superior or inferior thyroid vessels and used for grafts up to $8 \mathrm{~cm}$. VFG is especially useful for kyphosis cases, in which laminectomy for a cervical spinal cord tumor has destroyed posterior structures. Patients generally have to wear a halo vest for about 3 months, which is the time required for bone union after VFG. However, orthosis should be used because the bones of patients with NF-1 are very osteoporotic. A free fibular graft requires a longer period of orthosis since bone union does not occur for a year or more [13]. Although previous reports have followed VFG for periods of 24-43 months $[1,9]$, this report describes the long-term outcomes and maintenance of cervical alignment after VFG.

NF-1 is an inherited autosomal dominant dysplastic disease caused by a mutation of the NF1 gene on chromosome 17, causing vascular abnormalities and other types of ectodermal and mesodermal dysplasia [14]. Major intracranial artery occlusions are a well-known effect of NF-1 [15], and a craniocervical vascular lesion developed in one of the two cases described in this report. Although the corrective surgery of the surgical deformity in case 2 may affect her vertebral rupture, vascular events in both cases were related to NF-1. Thus, even after the successful correction of kyphosis, it is important to monitor patients for indications of vascular events related to NF-1. 


\section{Conclusion}

Anterior fusion with VFG can achieve good bone union and maintain long-term alignment. However, it is important to watch for vascular events related to NF-1.

\section{Clinical Message}

Vascularized fibula strut grafts (VFG) in the cervicothoracic spine may be useful for patients with progressive NF-1-related kyphosis. However, it is important to watch for vascular events related to NF-1 in the long-term.

\section{References}

1. Melloh M, Hodgson B, Carstens A, Cornwall J. Vascularized fibula strut graft used in neurofibromatosis Type 1-related kyphosis: A case of almost complete reversal of deformityinduced tetraparesis. Evid Based Spine Care J 2013;4:5962.

2. Asazuma T, Yamagishi M, Nemoto K, Amako M, Osada M, Fujikawa K. Spinal fusion using a vascularized fibular bone graft for a patient with cervical kyphosis due to neurofibromatosis.J Spinal Disord 1997; 10:537-40.

3. Funasaki H, Winter RB, Lonstein JB, Denis F. Pathophysiology of spinal deformities in neurofibromatosis. An analysis of seventy-one patients who had curves associated with dystrophic changes. J Bone Joint Surg Am 1994;76:692-700.

4. Goldberg VM, Shaffer JW, Field G, Davy DT. Biology of vascularized bone grafts. Orthop Clin North Am 1987; 18:197-205.

5. Winter RB, Lonstein JE, Anderson M. Neurofibromatosis hyperkyphosis: A review of 33 patients with kyphosis of 80 degrees or greater.J Spinal Disord 1988;1:39-49.

6. Craig JB, Govender S. Neurofibromatosis of the cervical spine. A report of eight cases. J Bone Joint Surg Br 1992;74:575-8.

7. Curtis BH, Fisher RL, Butterfield WL, Saunders FP. Neurofibromatosis with paraplegia. Report of eight cases.J Bone Joint Surg Am 1969;51:843-61.

8. Bradford DS, Winter RB, Lonstein JE, Moe JH. Techniques of anterior spinal surgery for the management of kyphosis. Clin Orthop Relat Res 1977;128:129-39.
9. Addosooki AI, Alam-Eldin M, Abdel-Wanis Mel S, Yousef MA, Dionigi P, Kenawey MO. Anterior cervical reconstruction using free vascularized fibular graft after cervical corpectomy. Global Spine J 2016;6:212-9.

10. Bradford DS, Ganjavian S, Antonious D, Winter RB, Lonstein JE, Moe JH. Anterior strut-grafting for the treatment of kyphosis. Review of experience with fortyeight patients.J Bone Joint Surg Am 1982;64:680-90.

11. Nijland EA, van den Berg MP, Wuisman PI, van Royen BJ, Winters HA, van Ouwerkerk WJ. Correction of a dystrophic cervicothoracic spine deformity in Recklinghausen's disease. Clin Orthop Relat Res 1998;349:149-55.

12. Arai K, Toh S, Tsubo K, Nishikawa S, Narita S, Miura H. Complications of vascularized fibula graft for reconstruction of long bones. Plast Reconstr Surg 2002;109:2301-6.

13. Crawford AH. Neurofibromatosis in the pediatric patient. Orthop Clin North Am 1978;9:11-23.

14. Greene JF Jr., Fitzwater JE, Burgess J. Arterial lesions associated with neurofibromatosis. Am J Clin Pathol 1974;62:481-7.

15. Chono Y, Ueno K, Nunomura M, Ohta Y, Nomura M, Nakamura N. von Recklinghausen's disease associated with occlusion of bilateral middle cerebral artery, moyamoya phenomenon, and anterior communicating artery aneurysm. Report of an autopsy case. Neurol Med Chir $1985 ; 25: 209-14$.
Conflict of Interest: Nil

Source of Support: Nil

Consent: The authors confirm that informed consent was obtained from the patient for publication of this case report

\section{How to Cite this Article}

Kumagai G, Echigoya N, Wada K, Asari T, Toh S, Ishibashi Y. Anterior Fusion using a Vascularized Fibular Graft for Cervical Kyphosis Associated with Neurofibromatosis Type 1: A Report of Two Cases with Long-term Followup. Journal of Orthopaedic Case Reports 2021 January; 11(1): 97-100. 